Check for updates

Cite this: RSC Adv., 2017, 7, 48692

\title{
Activity and stability analysis of covalent conjugated lysozyme-single walled carbon nanotubes: potential biomedical and industrial applications
}

Z. Borzooeian, ${ }^{\text {*a }}$ M. E. Taslim, $^{\text {a }}$ G. Borzooeian, ${ }^{\text {b }}$ O. Ghasemit ${ }^{c}$ and M. Aminlari ${ }^{d}$

Conjugated protein-carbon nanotubes possess unique physicochemical properties that make them attractive to a wide range of applications. We explored the effects of covalent conjugation of lysozymes with single-walled carbon nanotubes (SWCNTs) on its activity and stability. Lysozyme was conjugated onto carboxyl-functionalized SWCNTs through carbodiimide method. Post conjugation changes of the enzyme were investigated using fluorescence measurements to generate plots of protein unfolding at 0 and $6 \mathrm{M}$ guanidine hydrochloride $(\mathrm{Gn}-\mathrm{HCl})$ concentrations. Free lysozyme showed a remarkable increase in the fluorescence intensity at $287 \mathrm{~nm}$ in addition to a red shift from 343 to $352 \mathrm{~nm}$. The emission spectrum of conjugated lysozyme showed a significant increase in the fluorescence intensity at $287 \mathrm{~nm}$ and a significant decrease in intensity at $348 \mathrm{~nm}$. These results confirmed that both tryptophan and phenylalanine residues have an important role in the fluorescence bulk of both free and conjugated lysozymes. Kinetic parameters of free and conjugated lysozyme activities ( $K_{M}$ and $V_{\text {max }}$ ), optimum $\mathrm{pH}$, thermal and $\mathrm{pH}$ stability, and stability in the presence of denaturant agents such as urea and salts were investigated. Changes were observed in $K_{M}$ and $V_{\max }$ from 4.8 to $5.6 \mathrm{mM}$ and 193 to $197 \mathrm{nmol} \mathrm{min}^{-1}$, respectively. Conjugated lysozyme showed a remarkable increase in $\mathrm{pH}$ stability in a range of 3.0 to 10.0 at $70{ }^{\circ} \mathrm{C}$. The results showed first-order inactivation kinetics for both forms of lysozyme with a rate constant of about $0.139 \mathrm{~min}^{-1}$ for 10 minutes of incubation at $70^{\circ} \mathrm{C}$ in the presence of $\mathrm{KCl}$ and $\mathrm{KSCN}$.

Received 29th June 2017

Accepted 10th October 2017

DOI: $10.1039 / c 7 r a 07189 b$

rsc.li/rsc-advances investigated to provide scaffold-based delivery systems for signalling molecules. Molecules such as low-molecular-weight drugs, oligonucleotides, and proteins stimulate cell migration, growth and differentiation. ${ }^{19}$ The resulted scaffolds of conjugated proteins with nanomaterials can be used in cell encapsulation in order to control and track where the enzymes and signalling proteins go and exactly what they do when they get there. Therefore, a wide range of research have focused on immobilizing proteins/biopeptides such as collagen, ${ }^{20-22}$ gelatin, ${ }^{23}$ laminin, ${ }^{24-26}$ chitosan, ${ }^{27-29}$ and Arg-Gly-Asp (RGD)containing peptides ${ }^{30,31}$ onto the surfaces of polymeric scaffolds to enhance the biocompatibility of the surface and improve their cytocompatibility. ${ }^{32}$ In addition, drug delivery, diagnostic imaging and bio-sensing are promising new technologies that are resulted from creating protein-nanomaterials conjugates. For design and fabrication of biocompatible polymers such as high-performance coronary artery stents, nanomaterial-protein conjugates have been evaluated and optimized. ${ }^{33}$

In biotechnology, protein and especially enzyme immobilization provides technical and economic advantages since the molecules can be used multiple times for the same reaction. Immobilized enzymes, in comparison with their soluble $\dagger$ Current affiliation is Takeda Pharmaceuticals, but this work was completed

before my employment at Takeda Pharmaceuticals Company Ltd.

${ }^{a}$ Department of Mechanical and Industrial Engineering, College of Engineering, Northeastern University, Boston, MA, USA. E-mail: z.borzooeian@northeastern.edu; borzooeianm@gmail.com

'Takeda Pharmaceuticals USA Inc., Cambridge, MA, USA

${ }^{d}$ Department of Biochemistry, School of Veterinary Medicine, Shiraz University, Shiraz, Iran 
counterparts, demonstrate enhanced stability under extreme conditions of temperature, $\mathrm{pH}$, salts, and denaturing solvents. Therefore, they have longer half-lives since they degrade less and recover better and they are suitable for continuous processes. ${ }^{34}$ With physical or covalent immobilization, ${ }^{35}$ enzyme catalytic stability is achieved without contaminating the final product with enzymes thus saving cost and reducing process steps for purification. ${ }^{36}$ Over the last decade, enzyme immobilization on nanomaterials has become more important in order to develop a better understanding of enzyme-nanomaterial interactions, and to design functional protein-nanomaterial engraftments. ${ }^{5}$ Immobilization of biomolecules on nanomaterials, which is achieved either by glutaraldehyde or carbodiimide is the most common methods for covalent conjugation. ${ }^{6,7}$ Several researchers have investigated immobilization of lipase on carbon nanotubes through adsorption in non-aqueous medium, ${ }^{8-11}$ lysozyme adsorption on mica, ${ }^{37}$ polyethylene surfaces, ${ }^{38}$ and silica surface, ${ }^{39}$ horseradish peroxidase adsorption on silica surfaces, ${ }^{40}$ polysaccharide-decorated particles, ${ }^{\mathbf{4 1}}$ and onto titanate nanowires. ${ }^{42}$

Single-walled carbon nanotubes (SWCNTs) are promising for robust supports for enzyme immobilization and stabilization since they possess unique structural, mechanical and thermal properties, chemical reactivity and ease of surface modification. ${ }^{12}$ They are remarkable candidates because of their high aspect ratio which leads to high enzyme loading. They have potential biotechnological applications in biosensors and nanoscaffolds development. ${ }^{\mathbf{1 3 - 1 5}}$ A number of papers have appeared with regard to the particular aspect of stabilization and proteinnanotubes interactions with the effect of non-adsorbed protein. ${ }^{\mathbf{1 6}}$ However, there is a need to further improve our knowledge on the effect of nanotubes on activity and stability of covalent immobilized proteins.

In our previous study, we evaluated the conjugation of chicken egg white lysozyme (EWL) with single-walled carbon nanotubes (SWCNTs) structurally. ${ }^{44}$ Lysozymes are a family of enzymes with antimicrobial activity. They are present in saliva, tears, egg white, and many animal fluids. They are characterized by their ability to damage the cell wall of bacteria. In the present contribution, enzyme-induced post immobilization changes of activity and stability were analysed using various spectroscopy techniques. Conjugated EWL-SWCNTs were chemically and biochemically compared with free enzyme using scanning electron microscopy (SEM) and fluorescence spectroscopy. The fluorescence changes of free lysozyme and conjugated EWLSWCNTs were characterized by tryptophan, tyrosine, and phenylalanine fluorescence measurements. The catalytic efficiency of the immobilized lysozyme, in terms of thermal and $\mathrm{pH}$ stability, and stability in the presence of denaturing agents such as guanidine hydrochloride, urea and salts were also studied.

\section{Materials and methods}

\section{Materials}

Lyophilized chicken egg white lysozyme (EC 3.2.1.17), EWL, were purchased from Inovatech Inc., (Abbotsford, BC, Canada). Micrococcus lysodeikticus cells (as salt-free, dry powders), MES [2-
( $N$-morpholino)ethanesulfonic acid] buffer, $N$-ethyl- $N N^{0}$-(3-(dimethylamino)propyl)carbodiimide hydrochloride (EDC) and all other chemicals were purchased from Sigma-Aldrich (St. Louis, MO, USA). Highly purified activated SWCNTs were synthesized by the plasma-enhanced chemical vapour deposition (PECVD) process. ${ }^{44}$ The SWCNTs' outer diameters were $1-3 \mathrm{~nm}$.

\section{Enzyme attachment onto SWCNTs}

Conjugated lysozyme-SWCNTs solution was prepared using a modified carbodiimide method. ${ }^{13,43}$ Activated SWCNTs $(1.0 \mathrm{mg})$ were dispersed in $1.0 \mathrm{ml}$ of $50 \mathrm{mM}$ of MES [2-(N-morpholino)ethanesulfonic acid] buffer solution at $\mathrm{pH} 6.2$ and then added to equal volume of $400 \mathrm{mM} N$-hydroxy succinimide (NHS) in MES [2-( $N$-morpholino)ethane sulfonic acid] buffer. After sonication of the mixture (MSE Ultrasonic Disintegrators, 150W, England) for 30 minutes, $20 \mathrm{mM} N$-ethyl- $N^{\prime}$-(3-(dimethyl amino)propyl)carbodiimide hydrochloride (EDC) was added to promote the coupling of NHS to the carboxylic functional groups of SWCNTs. The resulting mixture was centrifuged at $7000 \mathrm{rpm}$ for 15 minutes after stirring at $200 \mathrm{rpm}$ for 30 minutes. Then MES buffer was added to the remaining precipitate followed by removing supernatant. The enzyme solution (10 mg ml $\mathrm{mb}^{-1}$ in $10 \mathrm{mM}$ phosphate buffer, $\mathrm{pH} \mathrm{8)}$ was mixed in the nanotubes solution and sonicated for $c a .1$ minute to re-disperse the SWCNTs. The solution was then shaken overnight on an orbital shaker at $200 \mathrm{rpm}$ at room temperature to conjugate enzyme to the SWCNTs. The enzyme-SWCNTs suspension was then centrifuged. To remove all non-specifically adsorbed enzymes, washing was achieved three times with triply distilled water and once with $1 \%(\mathrm{v} / \mathrm{v})$ Tween-20. Control solution of nanotube-enzyme conjugates was prepared using the identical procedure in the absence of EDC and NHS. Conjugation was tracked by scanning of supernatant of EWLSWCNTs solution using a spectrophotometer (ULTEROSPEC PLUS, Pharmacia LKB Biotechnology, Sweden) for wavelength range 200-500 $\mathrm{nm}$. The chemical stability of conjugation was characterized using Fourier transform infrared spectroscopy (FTIR), (Shimadzu FTIR 8300 spectrophotometer). In our previous work, we have shown the related results. ${ }^{44}$ The size and diameter of the conjugated EWL-SWCNTs was prepared using a scanning electron microscope (SEM, Oxford, S360).

\section{Fluorescence measurements of free and conjugated lysozyme}

The excitation wavelength of the fluorescence was set at a wide range around 225-282 $\mathrm{nm}$ for free lysozyme and conjugated form of enzyme at room temperature with resolution $0.5 \mathrm{~nm}$, and scan rate $500 \mathrm{~nm} \mathrm{~min}{ }^{-1}$ with an incident angle of $90^{\circ}$. The emitted fluorescence was measured from 225 to $500 \mathrm{~nm}$ for all forms of enzyme at different concentrations of $\mathrm{Gn}-\mathrm{HCl}$ using a fluorescence spectrometer (PerkinElmer (Waltham, MA) LS 50 Luminescence Spectrometer). The protein concentration in all measurements was $36 \mu \mathrm{M}$ using Bradford protein assay.

\section{Determination of free and conjugated enzyme activity}

The activities of free and conjugated enzymes were measured using Imoto and Yagishita method. ${ }^{43}$ Nine milligrams of dried 
M. lysodeikticus cell walls was dissolved in $30 \mathrm{ml}$ potassium phosphate buffer (0.1 M, pH 7.0) solution. The cell wall suspension $(2.9 \mathrm{ml})$ was poured into a cuvette and incubated at $25{ }^{\circ} \mathrm{C}$ for $5 \mathrm{~min}$. Free lysozyme and conjugated form of the enzyme, at a concentration of $1 \mathrm{mg}$ protein, were dissolved in one $\mathrm{ml}$ phosphate buffer $(\mathrm{pH} 7)$ and added to the cuvette. Absorbance at $450 \mathrm{~nm}$ was then recorded. One unit of activity of lysozyme is defined as the decrease in the absorbance at $450 \mathrm{~nm}$ of $0.001 \mathrm{~min}^{-1}$ at $\mathrm{pH} 7.0$ and $25^{\circ} \mathrm{C}$ using M. lysodeikticus cells as a substrate.

\section{Kinetic characterization of conjugated and free enzyme}

Kinetic parameters of free and conjugated lysozymes were determined using 0, 0.04, 0.06, 0.08, 0.15, 0.25 and $0.6 \mathrm{mg} \mathrm{ml}^{-1}$ of $M$. lysodeikticus cell wall in $0.1 \mathrm{M}$ potassium phosphate buffer (pH 7.0) at room temperature, respectively. The Michaelis constants, $K_{\mathrm{M}}$ and $V_{\max }$ for the free and conjugated lysozyme preparations were determined using Lineweaver-Burk plot. Then the turnover number $\left(K_{\text {cat }}\right)$ was determined.

\section{Optimum pH and thermal stability of free and conjugated lysozyme}

The optimum $\mathrm{pH}$ for lysozyme activity was studied over a $\mathrm{pH}$ range of 3 to 8.5 to determine the activity of free as well as conjugated enzyme. Citrate buffer ( $\mathrm{pH} 3-6)$, phosphate buffer $(\mathrm{pH}$ 7-8), and bis-Tris propane buffer ( $\mathrm{pH}$ 6.3-9.5) were used to determine enzyme activity. The stability of the enzyme was determined by preincubating the enzyme for $30 \mathrm{~min}$ at $37^{\circ} \mathrm{C}$ with various buffers. After incubation, the residual enzyme activity (\%) was measured using phosphate buffer $(0.1 \mathrm{M}, \mathrm{pH} 7.0)$. The thermal stability of the enzyme was studied by preincubating the enzyme at $70{ }^{\circ} \mathrm{C}$ for 0-20 minutes range at optimum $\mathrm{pH}$.

\section{Effect of KCl and KSCN on thermostability of free and conjugated lysozymes}

Heat-induced aggregation and inactivation of free and conjugated lysozyme in the presence of $\mathrm{KCl}$ and $\mathrm{KSCN}$ (as a strong chaotropic salt) was evaluated by heating stock solution containing $1.0 \mathrm{mg} \mathrm{ml}^{-1}$ of lysozymes in $0.1 \mathrm{M}$ phosphate, $\mathrm{pH} 7.0$ and 1.0 $\mathrm{M}$ salts at $70{ }^{\circ} \mathrm{C}$ for various time intervals.

\section{Effect of urea on stability of free lysozyme and EWL-SWCNTs}

$400 \mu \mathrm{l}$ from lysozyme and EWL-SWCNTs solutions $\left(1 \mathrm{mg} \mathrm{ml}^{-1}\right)$ were incubated in the presence of $2,4,6$ or $8 \mathrm{M}$ urea in $0.1 \mathrm{M}$ phosphate buffer, pH 7.0. Enzymes were assayed after 0, 30, 60, 90 and 120 minutes. Solutions containing urea were prepared fresh each time.

\section{Results and discussion}

The main objective of this study was to investigate the influence of covalent conjugation of lysozyme onto SWCNTs on the enzyme structure, function, and stability in order to evaluate the efficiency of functionalized nanotubes as a support for enzyme immobilization.
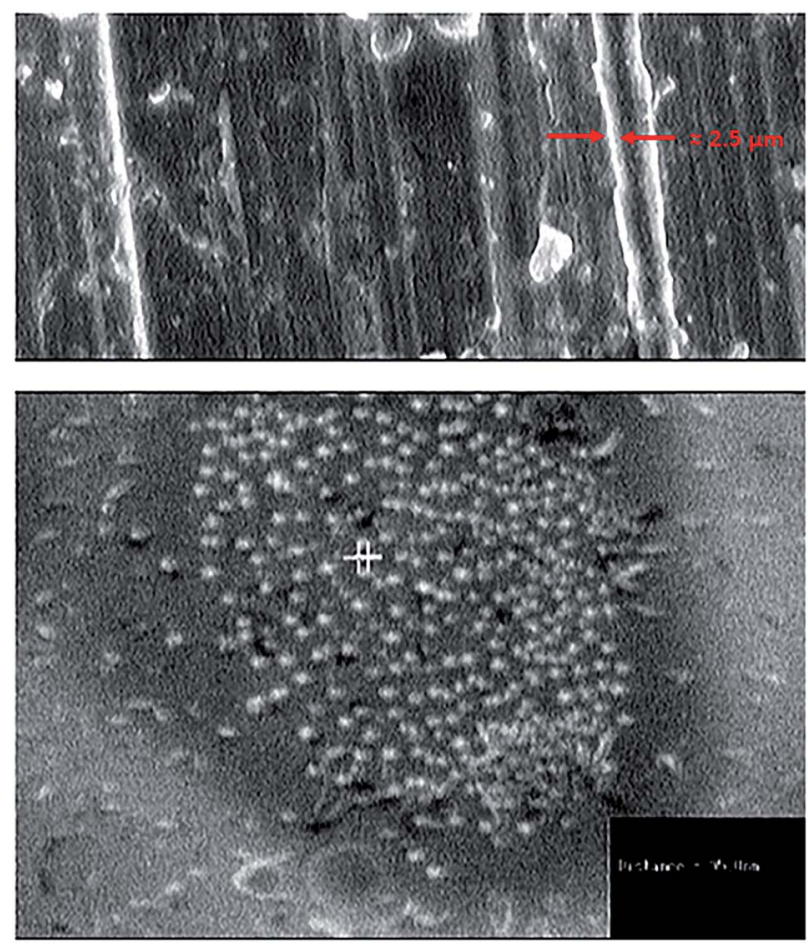

Fig. 1 Scanning electron micrographs of conjugated lysozymeSWCNTs (a) diameter of a bundle of lysozyme-SWCNTs $\approx 2.5 \mu \mathrm{m}$, (b) average diameter of each conjugated lysozyme-SWCNTs $=95 \mathrm{~nm}$.

Enzyme loading onto nanotubes (covalently or noncovalently) was confirmed by the disappearance of the absorption peak at $280 \mathrm{~nm}$ in the supernatant of conjugated enzyme solution after precipitation of conjugated EWL-SWCNTs in the cuvette. In addition, the efficient conjugation have been evaluated using analytical techniques such as TEM, agarose gel electrophoresis, XRD and FTIR spectroscopy which we reported in our previous work. ${ }^{44}$ We determined that lysozyme would covalently bind to the surface of the SWCNTs through amino groups of lysozyme side chains. Fig. 1 shows the SEM micrographs and the size of conjugated EWL-SWCNTs.

Increase in the thickness of the sidewalls of the functionalized SWCNTs, after covalently conjugated enzyme, confirmed the presence of enzyme. Similar observations of adsorption of lysozyme molecules onto the hydrophilic silica surface have been reported. ${ }^{45}$

\section{Fluorescence measurements}

To complete the characterization of enzyme conjugation, we compared fluorescence measurements using tryptophan, tyrosine and phenylalanine as important intrinsic fluorescent probes, which can be used to estimate the nature of microenvironment of these amino acids and probe for protein folding. ${ }^{46}$ The main purpose was to study the effect of guanidine hydrochloride $(\mathrm{Gn}-\mathrm{HCl})$ on the florescent intensity of lysozyme in its free lysozyme and conjugated form. The fluorescence intensity and maximum emission wavelength $\left(\lambda_{\max }\right)$ are affected by the polarity and charge densities surrounding tryptophan, tyrosine and phenylalanine residues. ${ }^{46}$ Imoto et al. showed two buried 
tryptophan residues at positions 62 and 108 which interpret fluorescence changes in the protein. Because of these aromatic residues, fluorescence changes have more direct correlation with major tertiary structural changes in the protein. ${ }^{47}$ For lysozyme, however, presence of multiple tryptophan, tyrosine and phenylalanine complicates the interpretation of fluorescence changes. Therefore, there is not a direct correlation between fluorescence changes and bulk tertiary changes of the protein. This egg white protein has six tryptophan residues, several of which are known to be near the active site, and two tyrosines and two phenylalanines. ${ }^{48}$

Surfactants, denaturants, or other amphiphilic molecules can change the microenvironment of the aromatic residues. Microenvironment alteration of tryptophan and phenylalanine residues in free and conjugated lysozymes has been monitored by studying the changes $\left(\lambda_{\max }\right)$ in 0 and $6 \mathrm{M} \mathrm{Gn}-\mathrm{HCl}$ concentrations (Fig. 2a-c). Emission efficiency was reached in the wavelength range of 225-282 $\mathrm{nm}$ excitation for both free and conjugated enzymes. By selecting a range of excitation, the possibility of missing the optimum emission peaks for both forms of proteins is reduced. For free lysozyme, to our surprise, we found that the fluorescence intensity at $286 \mathrm{~nm}$, which is the maximum emission wavelength $\left(\lambda_{\max }\right)$ of phenylalanine, ${ }^{49}$ significantly increased at $6 \mathrm{M}$ of $\mathrm{Gn}-\mathrm{HCl}$, Fig. 2a. Indeed, there are no existing investigations to figure out the exact reason for the intensity change at $286 \mathrm{~nm}$. This subject should be the focus of future research to determine fluorescence of lysozyme using emission spectra of tryptophan, tyrosine, and phenylalanine residues and from energy migration.

In Fig. 2b, the emission spectrum of EWL-SWCNTs showed significantly increased fluorescence intensity at $286 \mathrm{~nm}$ and a decreased intensity at $340 \mathrm{~nm}$ in comparison with the free lysozyme.

The first observation is related to the peak at around $350 \mathrm{~nm}$ associated with tryptophan, in which the conjugated lysozyme has much lower emission distribution than the free protein. We speculate that SWCNTs change the structure of the protein, specifically at tryptophan sites, such that the emission intensity decreases by over 5 folds. Moreover, the emission maximum wavelength $\left(\lambda_{\max }\right)$ is red shifted for both form of enzymes as the protein encounters high Gn-HCI concentration. This effect can be due to more exposure of the tryptophan residues to an aqueous environment in the presence of high concentration of denaturant that leads to the higher polarity of the tryptophans' microenvironment.

Second, the aforementioned structural change does not affect the emission spectrum of phenylalanine. As shown in the figure and described in the previous section, by adding Gn-HCI, the intensity of the peak at $286 \mathrm{~nm}$ for both free and conjugated form of lysozyme increases by around 5 and 6 folds, respectively. The results indicate that conjugation with SWCNTs completely converted microenvironments of phenylalanine residues (an increased intensity in $283 \mathrm{~nm}$ ) and tryptophan residues (a decreased intensity) in conjugated form, which leads to more exposure of these amino acids to a more polar environment. This fact indicates that the protein conformation is getting altered in both forms. To figure out the reasons for

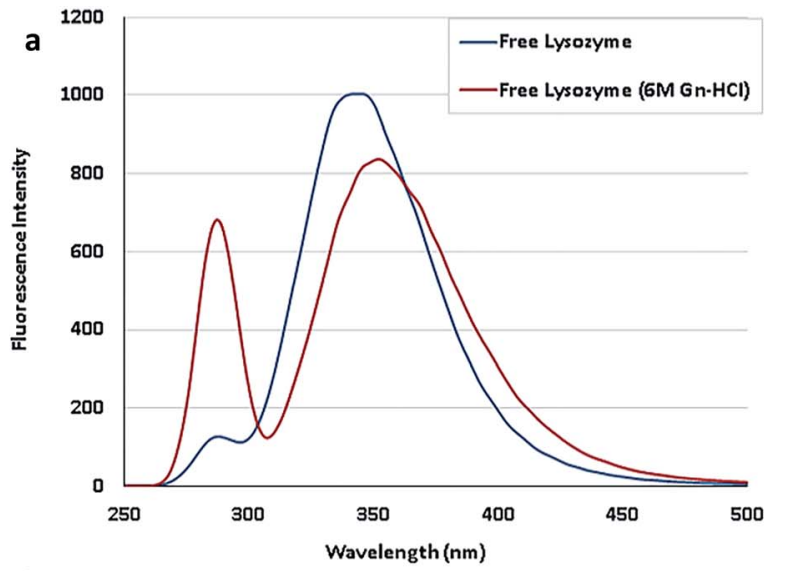

b

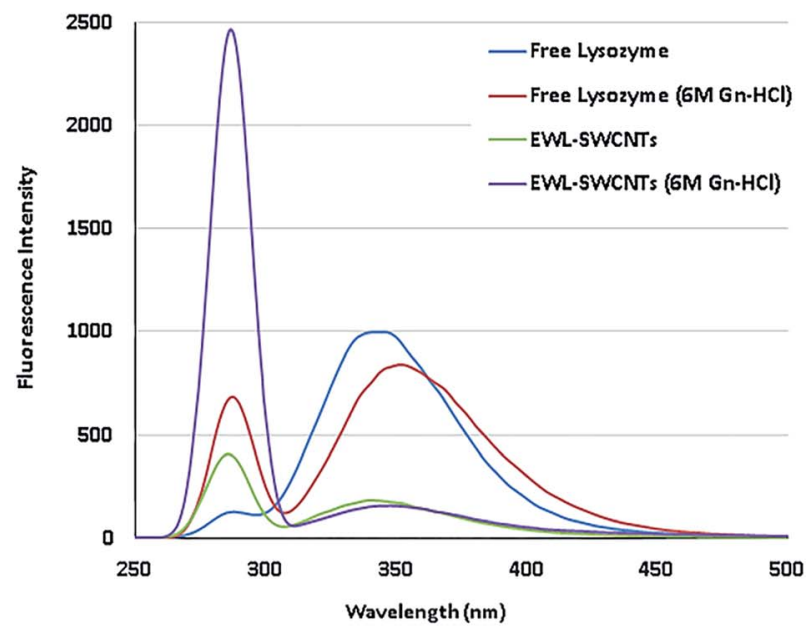

C Emission spectra of unfolding of conjugated lysozyme

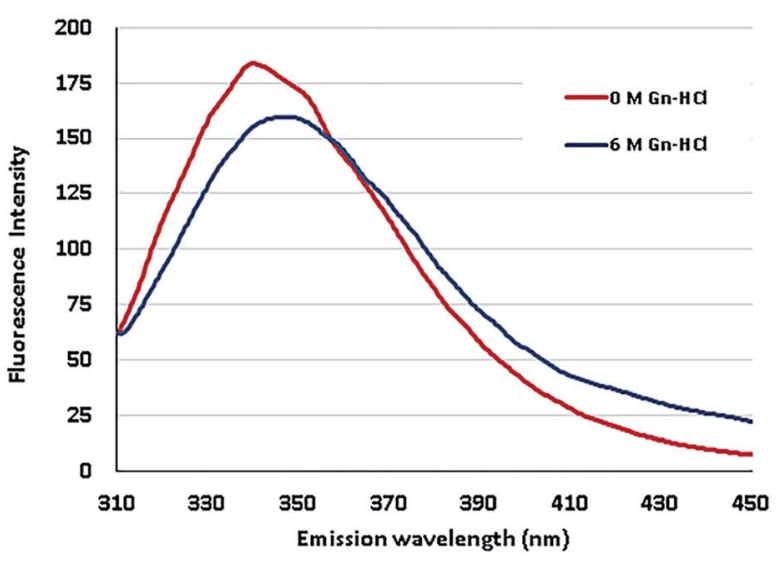

Fig. 2 (a) Emission spectra of lysozyme unfolding. (b) Emission spectra of free and conjugated lysozymes in 0 and $6 \mathrm{M}$ concentrations of Gn$\mathrm{HCl}$. (c) Spectral shift of conjugated EWL-SWCNTs unfolding.

fluorescence intensity changes of EWL-SWCNTs, more extensive research are needed to determine the locations of lysozyme fluorescence bulks.

Since the emission peaks of SWCNTs are higher than $900 \mathrm{~nm},{ }^{50}$ we believe that this remarkable increase of intensity at $286 \mathrm{~nm}$ is attributed to the fluorescence change of 
phenylalanine 20 and 53. Phenylalanine is one of the three fluorescent amino acids in proteins. Its use, however, is limited in protein structural studies because of its low fluorescence quantum yield (about 0.02). ${ }^{48}$ Birch et al. ${ }^{49}$ showed the decays of excite measurable fluorescence for this weakly fluorescent amino acid using a $265 \mathrm{~nm}$ AlGaN light-emitting diode (LED) from 343 to $352 \mathrm{~nm}$ at $6 \mathrm{M}$ of $\mathrm{Gn}-\mathrm{HCl}$. Fig. 2c shows the spectra of EWL-SWCNT at $6 \mathrm{M}$ of $\mathrm{Gn}-\mathrm{HCl}$.

The emission spectra of EWL-SWCNTs resulting from $282 \mathrm{~nm}$ of excitation wavelength used to measure transient fluorescence spectra at 0 and $6 \mathrm{M}$ concentrations of $\mathrm{Gn}-\mathrm{HCl}$. The results shows that decrease in the intensity at $340 \mathrm{~nm}$ due to increased concentration of $\mathrm{Gn}-\mathrm{HCl}$ indicates quantum yield change of those buried phenylalanine residues in the hydrophobic cores in the structure of conjugated enzyme. Therefore, there is a change in enzyme folding under these conditions. In our work, the reading of red $(340 \mathrm{~nm})$ increased and shifted from 340 for free lysozyme to $347 \mathrm{~nm}$ at $6 \mathrm{M}$ concentration of Gn-HCI. This reduced shift of wavelength is probably due to protein unfolding or/and absorption of the emitted red fluorescence by the SWCNTs. One possible reason is that the tryptophan residues 62 and 108 in conjugated lysozyme were less accessible to the solvent.

Fig. 3 represents maximum fluorescence intensity monitored in excitation at $286 \mathrm{~nm}$ (peak 1) and $340 \mathrm{~nm}$ (peak 2) for free and conjugated enzymes in 0 and $6 \mathrm{M} \mathrm{Gn}-\mathrm{HCl}$ concentrations. The figure shows that by adding Gn-HCI, there is not a significant change in the maximum fluorescence intensity of any forms of lysozyme at peak 2 due to the hydrophobic environment experienced by tryptophan. On the other hand, the maximum intensity increased dramatically at peak 1 by adding Gn-HCI to the compound. Adding Gn-HCI increases the intensity of peak 1 for both free and conjugated form of lysozyme by around 5 and 6 folds, respectively. It is also observed that peak 1 in the conjugated

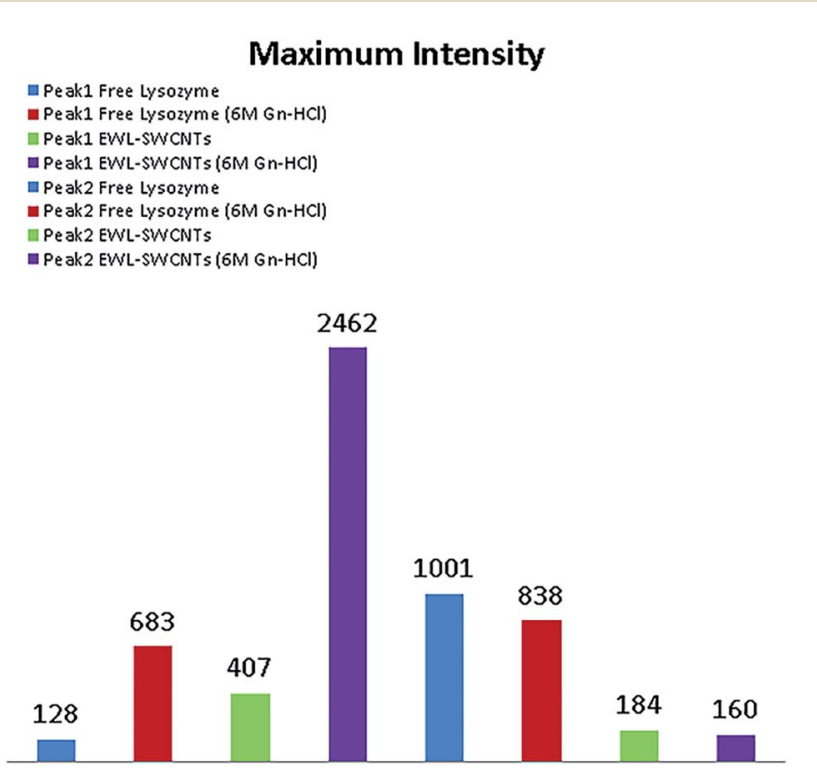

Fig. 3 Maximum intensity of free and conjugated form of lysozyme at peak 1 and 2 . form of lysozyme at $6 \mathrm{M} \mathrm{Gn-HCI}$ is almost 4 folds higher than that of free lysozyme.

\section{Determination of enzyme activity}

Lysozyme activity assay was performed with the M. lysodeikticus cell walls as substrate. For EWL-SWCNTs, the activities were lower than that of free enzyme, probably due to the partially unfolded 3D structure. Covalent interaction between lysozyme and SWCNTs could significantly affect the active site situation, structure, and function of lysozyme. ${ }^{51}$ The ionizable groups in active site consist of the side chain of glutamic acid and aspartic acid at positions 35 and 52, respectively, ${ }^{52}$ and aspartic acid groups at position 66 and $101 .^{53}$ Steric hindrance and change in the position of carboxylic groups of active site might be responsible for the decrease in lytic activity of conjugated lysozyme. Basically, it is well documented that the surface properties of molecules change due to the attachment of groups to proteins leading to changes in protein conformation, unfolding, molecular reorientation and aggregation. ${ }^{\mathbf{5 4 5 5}}$

\section{Kinetic characterization of immobilized and free enzyme}

Kinetic parameters of free and conjugated lysozyme were determined by measuring initial reaction rates for each form by varying the amount of substrates (M. lysodeikticus cell walls). Conjugated and free lysozymes exhibited Michaelis-Menten kinetic behavior (Fig. $4 \mathrm{a}$ and b). The maximum velocity $\left(V_{\max }\right)$ and $K_{\mathrm{M}}$ were calculated from the $y$-intercept and $x$-intercept from Lineweaver-Burke graph. $K_{\mathrm{M}}$ value of the EWL-SWCNTs was $5.6 \mathrm{mM}$, and for free enzyme was $4.8 \mathrm{mM}$. Indeed, conjugated enzyme showed a higher $K_{\mathbf{M}}$ value $(P<0.05)$ with respect to the free enzyme, indicating lower affinity of enzyme for its substrate. Maximum velocity of the free and conjugated

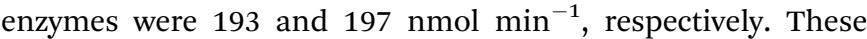
changes in the kinetic parameters indicate that covalent binding of lysozyme onto SWCNTs resulted in change of affinity for the substrate. This may be due to moderately decreased substrate access to the active site of the conjugated enzyme. Conformational changes in the protein, which can result in changes in enzyme activity and affinity for the substrate occur because of covalent binding of lysozyme during immobilization. ${ }^{57}$

\section{Thermal stability of free and conjugated lysozyme}

Relative activities of free and conjugated lysozymes before and after thermal treatment at $70{ }^{\circ} \mathrm{C}$ for 20 minutes are shown in Fig. 5. The results showed that the thermal stability of the lysozyme was improved through conjugation onto SWCNTs. Residual activity of the free enzyme was approximately $20 \%$ after 20 minutes of incubation at $70{ }^{\circ} \mathrm{C}$ whereas the conjugated lysozyme retained $60 \%$ of its initial activity after 20 minutes of incubation. Predominantly, immobilization enhances the enzyme thermal stability due to a decrease in the protein structure mobility and an increase in rigidity protects enzyme from stability, specifically thermal stability of enzymes. ${ }^{56}$ The increased thermal stability for the conjugated enzyme can be due to the effects of the environment. ${ }^{57,58}$ Limited structural 

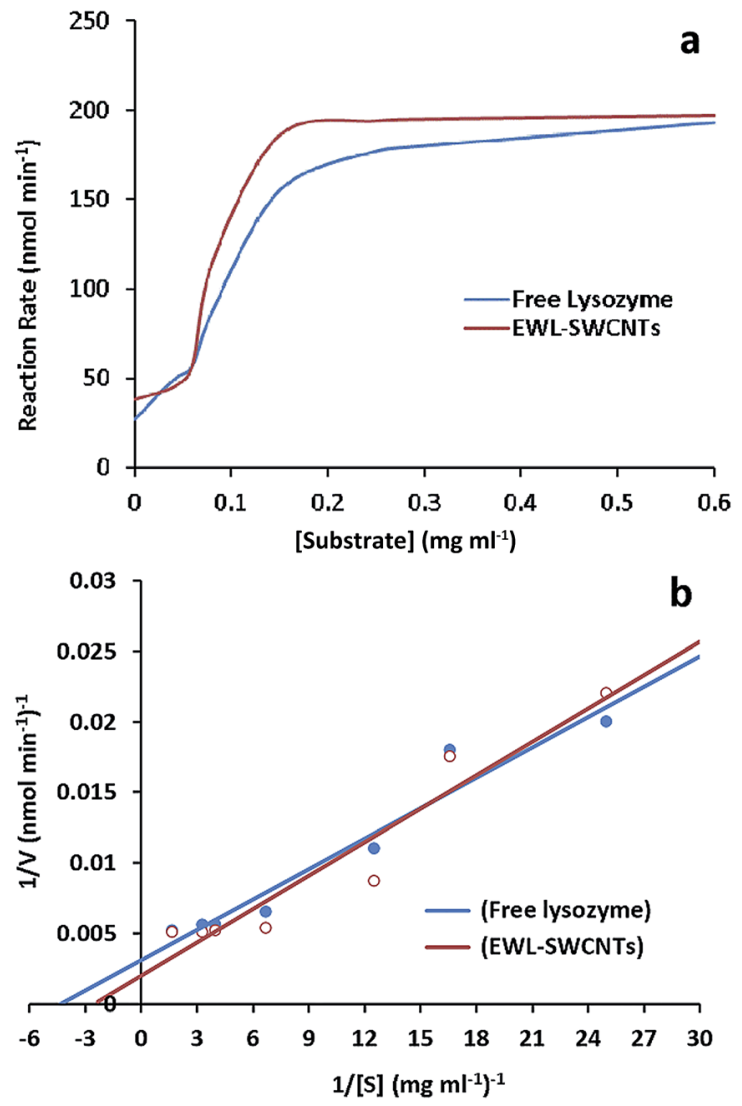

Fig. 4 (a) Effect of substrate concentration on the specific activity of free lysozyme and EWL-SWCNTs. (b) Double reciprocal plot of velocity and substrate concentration for determination of $K_{M}$ and $V_{\max }$ values of lysozyme in both free and conjugated enzymes.

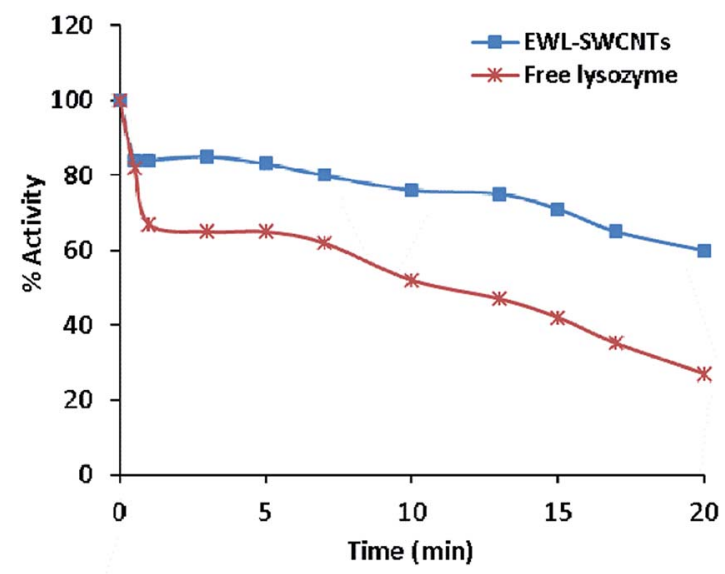

Fig. 5 Thermostability of free lysozyme and conjugated EWLSWCNTs. The enzymes solutions were incubated at $70{ }^{\circ} \mathrm{C}$. Residual activities were measured using Imoto and Yagishita method. The initial activity is denoted as $100 \%$.

mobility due to covalent bonds and anchorage to the nanotubes increases thermal stability of immobilized lysozyme. In this case, a study showed that the thermal stability and catalytic activity of enzymes were significantly improved by enzyme-

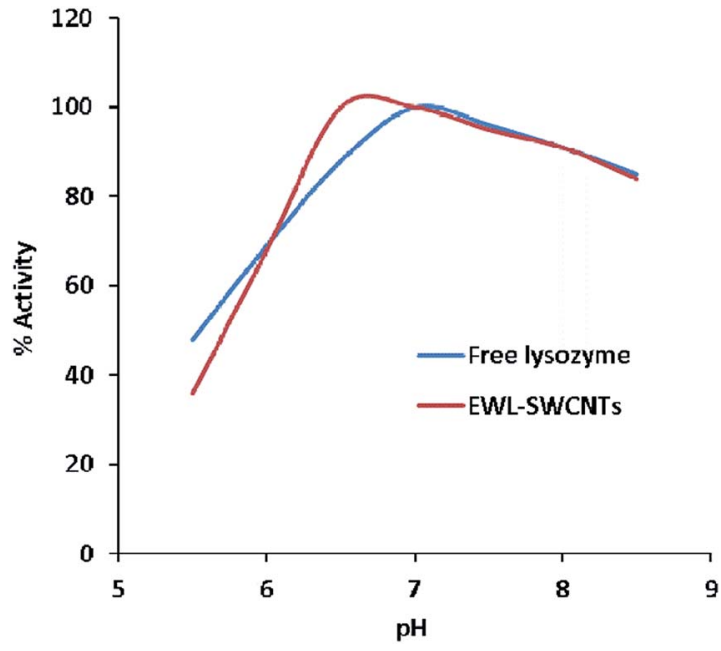

Fig. 6 The optimal pH for free and conjugated lysozymes.

carbon nanotube interactions. ${ }^{7}$ We previously reported ${ }^{44}$ that the effect of amid bonds in conjugation with coupling agent (carbodiimide) to SWCNTs played an important role in improving the catalytic property of immobilized enzyme. The results obtained in this study suggest that covalent conjugation of lysozyme to SWCNTs can sterically prevent enzyme from heat-induced unfolding.

\section{Optimum $\mathrm{pH}$ of free and conjugated lysozyme}

The $\mathrm{pH}$ activity profile of free and conjugated lysozymes are shown in Fig. 6. The optimum pH of these forms of enzymes was studied at a $\mathrm{pH}$ range of 5.5-8.5. The results showed that the optimum $\mathrm{pH}$ values of free and conjugated lysozymes were 7.0 and 6.5, respectively. The $\mathrm{pH}$ shift towards the acidic value upon conjugation is speculated to be due to amide bonds between the amino groups of enzyme and the carboxylic groups of SWCNTs. Amphoteric properties of the enzyme depends on the ionizable groups in its active site. The charges on these groups depend on their accessibilities to the environment in different $\mathrm{pH}$ ranges. Variations in the $\mathrm{pH}$ lead to the changes in the ionic form of the active site and, consequently, changes in the activity of the enzyme. It seems that conjugation with SWCNTs affects the total net charge of the enzymes, distribution of charge on their exterior surfaces, and reactivity of the active groups. These effects are especially important in the vicinity of the active sites. The changes in lysozyme activity due to conjugation in different $\mathrm{pH}$ ranges can be explained by the change of charges of the four ionizable groups in the active site which are involved during catalysis. The ionizable groups consist of the side chain of glutamic acid at positions 35 and 66, and aspartic acid at positions 52 and 101, respectively. ${ }^{53}$

\section{Evaluation of pH stability of the free and conjugated enzymes}

The $\mathrm{pH}$ stability of free and conjugated lysozymes were compared at different $\mathrm{pH}$ values $(2.0,3.0,5.0,7.0$, and 10.0) after incubation for 1, 2, and 3 hours. Enzyme activity was measured at the $\mathrm{pH} 7$ (Fig. 7a-c). The results indicated that 

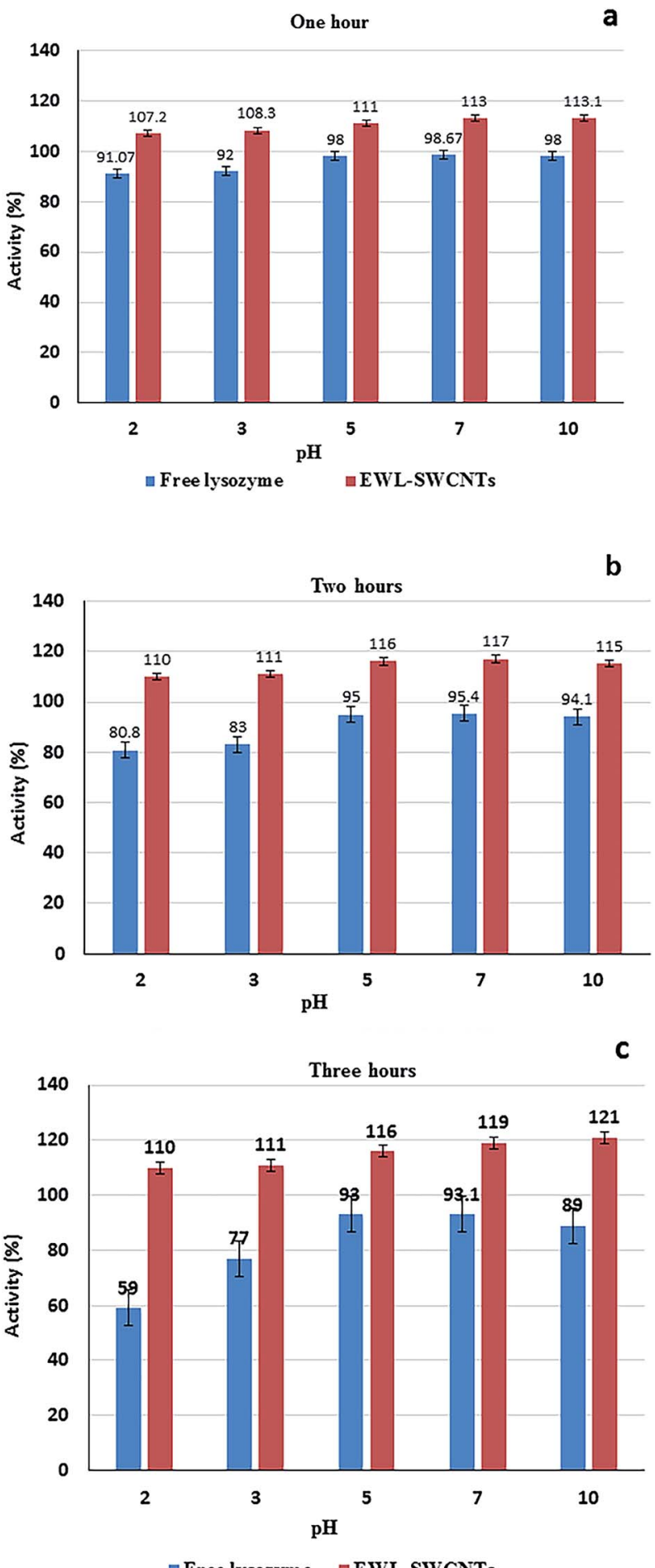

Fig. 7 Evaluation of pH stability of free and conjugated lysozymes. The solutions in mix buffer (Tris-base, MES, and acetate) were incubated at $\mathrm{pH} \mathrm{2,} \mathrm{3,} \mathrm{5,} \mathrm{7,} \mathrm{and} 10$ in $70{ }^{\circ} \mathrm{C}$ for (a) one, (b) two, and (c) three hours. Enzyme activity was measured at $\mathrm{pH} 7$.

conjugated enzyme had the highest stability at $\mathrm{pH} 2.0,7.0$, and 10.0 after 1 hour of incubation. At pH 2.0, however, the highest stability retained after 2 and 3 hours of incubation. The free lysozyme, however, had the highest stability around $\mathrm{pH} 5$ to 7 after 1,2 , and 3 incubation hours. Significant increase in stabilization of the conjugated enzyme in the wide $\mathrm{pH}$ range of 2 to 10 , after 3 hours shows the role of the SWCNTs in stabilizing the enzyme. The increased stability confers some level of protection to the enzyme during the reaction either in acidic or alkaline environment. Different factors affect $\mathrm{pH}$ stability, including temperature, ionic strength, enzyme concentration, chemical nature of the buffer, concentration of various preservatives (e.g. glycerol and sulfhydryl compounds), concentration of substrates and cofactors. In addition, $\mathrm{pH}$ stability of proteins is altered by multiple mechanisms including salt-bridge forming/breaking, hydrogen bond interactions, and likecharge repulsion effects. ${ }^{59}$ Salt bridges are pH-dependent and non-covalent bonds between oppositely charged residues that are adequately close to each other to create electrostatic bonds. In tertiary structure of proteins, salt bridges are constituted from negative charges from aspartic acid, glutamic acid, tyrosine, cysteine and the C-terminal carboxylate group, and of positive charges from lysine, arginine and the N-terminal amino groups. ${ }^{60}$ We believe that increased stability of EWL-SWCNTs can occur due to the formation of more interior salt bridges and also change of charge distribution on the exterior surfaces of the protein. Cannon et al. ${ }^{61}$ showed a statistically significant clustering of charged residues as ion-pairs and salt-bridge networks. Thermophilic proteins have more salt bridges than their mesophilic counterparts. ${ }^{62,63}$ In their study, $\mathrm{p} K_{\mathrm{a}}$ shifts showed that in buried salt bridges, stability decreased by 3$5 \mathrm{kcal} \mathrm{mol}^{-1}$ by removing a charge from one residue. ${ }^{64,65}$ It indicates that immobilization impact on stability was caused by charge change in the structure of proteins. Our results demonstrate that conjugation with SWCNTs have impact on residue charges, electrostatic bonds, the number of salt bridges and ion-pairs, geometrical orientation of the charged side chain in the salt bridges, and, consequently, on the folding and 3D structure of lysozyme.

\section{Effect of KCl and KSCN on the thermostability of free and conjugated lysozymes}

Fig. 8a and b show representative data for the thermostability of lysozyme $\left(1.0 \mathrm{mg} \mathrm{ml}^{-1}\right.$ phosphate buffer, $0.1 \mathrm{M}$ and $\left.\mathrm{pH} 7\right)$ in the presence of $\mathrm{KCl}$ and $\mathrm{KSCN}(1.0 \mathrm{M})$ at $70{ }^{\circ} \mathrm{C}$.

After heat treatment for 10 minutes, both free lysozyme and conjugated EWL-SWCNTs retained $20 \%$ and $10 \%$ activities in the presence of $\mathrm{KCl}$ and $\mathrm{KSCN}$, respectively. Both free and conjugated forms of enzyme were inactivated with first-order kinetics at a rate constants of about $0.139 \mathrm{~min}^{-1}$ for 10 minutes. There are a number of research studies focusing on the role of salts during the heat induced proteins unfolding. ${ }^{56,60-64}$ However, the role of salts on heat-induced unfolding of conjugated enzyme with SWCNTs has not been studied to the same extent. To study the role of anions on thermal stability of proteins in free and SWCNT-conjugated forms, unfolding reaction should be investigated. These reactions consist of breaking noncovalent bonds between polypeptide chains (which include a combination of hydrogen bonds, van der Waals forces, and salt bridges), hydrating the newly exposed hydrophobic core of the protein and finally denaturing the 

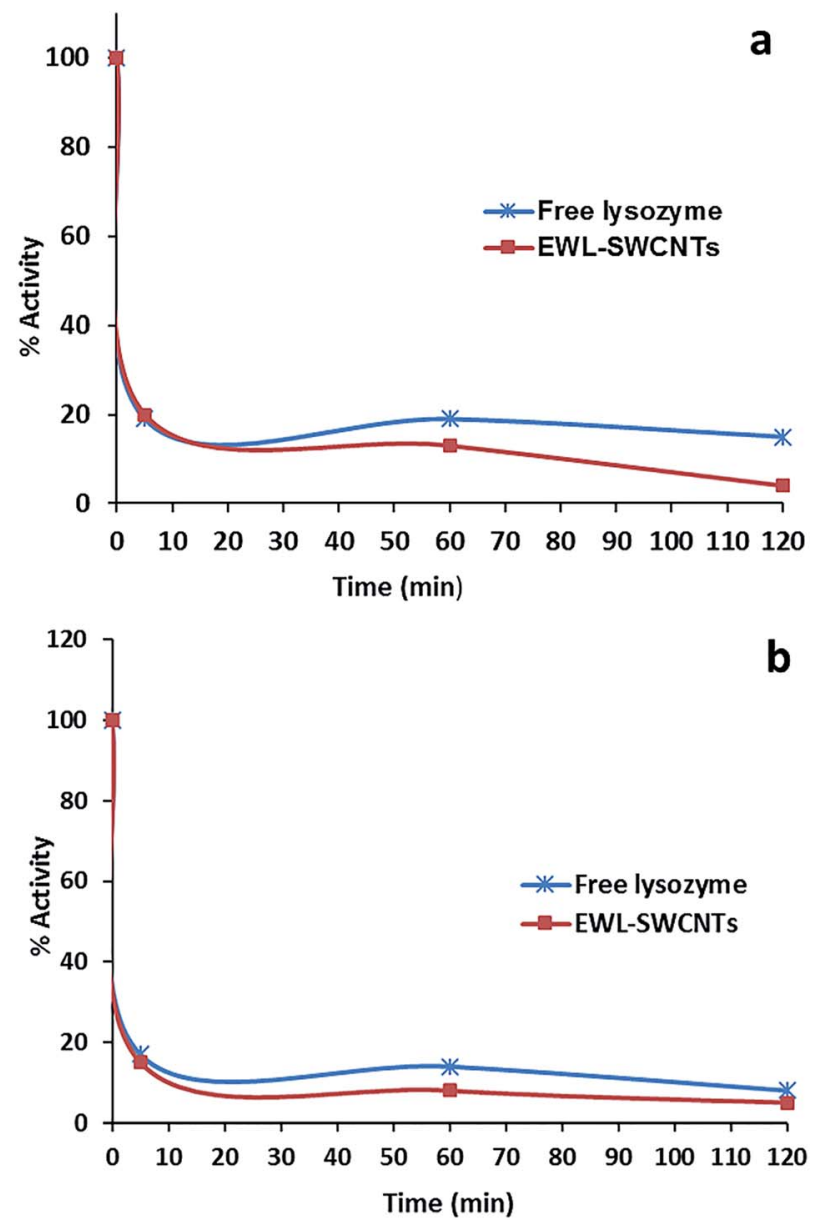

Fig. 8 Effect of (a) KCl (1 M) and (b) KSCN (1 M) on thermostability of free lysozyme and EWL-SWCNTs at $70{ }^{\circ} \mathrm{C}$.

secondary structure sections - alpha helices and beta pleated sheets, held together by hydrogen bonds. ${ }^{65}$ At $\mathrm{pH} 7$, free lysozyme has a positive net charge of around $+8{ }^{66}$ Positively charged amino acid side chains of lysine, arginine and histidine may electrostatically be covered by the anions $\left(\mathrm{Cl}^{-}\right.$and $\left.\mathrm{SCN}^{-}\right)$if they are accessible and not sterically hindered. The effect of these interactions on the structural stability of the protein depends on local conditions of the protein surface. Bye et al. ${ }^{67}$ suggest three mechanisms - electrostatic interaction at low concentrations, weak interaction with polar residues, and competition for water of hydration, by which anions regulate lysozyme stability. At high concentration of salts, anions compete for water with the enzyme molecules. Ionic dispersion potential is an important source of ion specificity which acts between each ion and protein. ${ }^{62}$ Boström et al. showed that this attractive potential is much stronger for $\mathrm{SCN}^{-}$than it is for $\mathrm{Cl}^{-}$. Our results also confirmed more ionic dispersion potential for KSCN (Fig. 8b).

\section{Effect of urea on stability of free and conjugated lysozymes}

The activity measurements of free and conjugated lysozyme in aqueous solutions in the presence of urea are reported in Fig. 9a and $b$. The comparison of these figures indicates that free lysozyme retained $30 \%$ activity, whereas the conjugated enzyme retained 10\% activity in the presence of 2, 4, 6 and 8 molar urea. Both free and conjugated forms of the enzyme were inactivated with first-order kinetics at a rate constants of about $0.069 \mathrm{~min}^{-1}$ for $20 \mathrm{~min}$. A second important observation from Fig. 9 is that, in comparison with free lysozyme, the EWL-SWCNTs showed a higher loss of activity (about 90\%) for all urea concentrations. Hédoux et al. ${ }^{68}$ showed a lysozyme tertiary structure transformation into a softer structure without unfolding of the secondary structure because of binding urea molecules to hydrophilic residues. The significant decrease in conjugated lysozyme activity in all urea concentrations is due the changes in both positions and charges of hydrophilic residues which results in a significant conformational structure change of conjugated lysozyme. A number of researchers have proposed two mechanisms, "direct" and "indirect" models, to explain how urea induces the unfolding of the protein and changes the protein-water/protein-protein interaction balance. ${ }^{68-71}$ Urea molecules are absorbed by the charged hydrophilic residues on the surface, which causes the protein swelling. In addition, urea
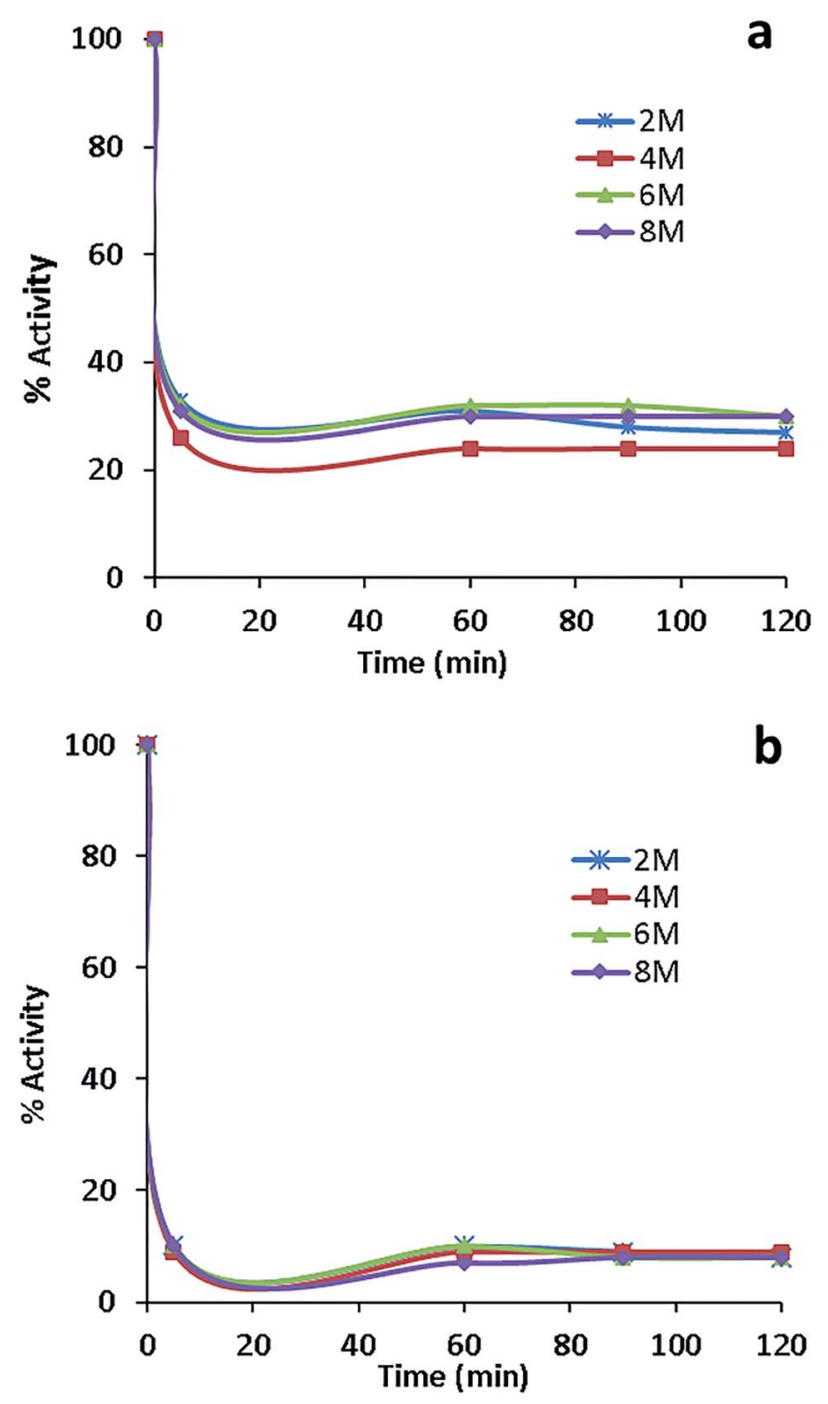

Fig. 9 Effect of urea on the activity of (a) free lysozyme and (b) conjugated lysozyme. 
intrudes the protein followed by water entering the hydrophobic core. Therefore, it causes exposure of hydrophobic residues to the polar environment ${ }^{72}$ thus unfolding of the protein. Tirado-Rives et al. ${ }^{73}$ showed that a model in which urea directly binds to the amide units via hydrogen bonds and consequently denatures proteins by decreasing the hydrophobic effect. Our results suggest that conjugation with SWCNTs leads to more accessibility of charged hydrophilic residues on the surface through conjugation and consequently more interaction with urea molecules. This idea is confirmed by molecular dynamics simulations ${ }^{72}$ as well as Raman spectroscopy by Bennion et al. ${ }^{74}$ who detected the strong enhancement of isotopic exchanges in the presence of a high urea content ( $>4$ $\mathrm{M})$ in the amide I region. These results can be considered as evidences of direct interaction of urea with polar residues and the lysozyme backbone. Consequently, there will be high density of urea molecules on the surface of the protein, which results in more intense unfolding. The conformational changes in the conjugated lysozyme structure needs more studies using Raman spectroscopy.

\section{Conclusions}

Conjugated protein-carbon nanotubes are extensively used as biophysical and biochemical tools in the area of biomedicine and biotechnology. Covalent conjugation of proteins on carbon nanotube surfaces, while retaining their structure, function and stability is a significant process in bionanofabrication technology. High chemical stability of conjugated lysozyme was confirmed by FTIR, SEM, and agarose gel electrophoresis. ${ }^{44}$ The results of this study confirmed the excellent potential of the SWCNTs as a support for enzyme immobilization. The fluorescence spectra confirmed, rather surprisingly, the role of both phenylalanine and tryptophan residues in the fluorescence bulk of the conjugated lysozyme. Compared with the free lysozyme, the emission spectrum of conjugated EWL-SWCNTs showed a significant increase in the fluorescence intensity at $286 \mathrm{~nm}$ (emission wavelength $\left(\lambda_{\max }\right)$ of phenylalanine $\left.\mathrm{e}^{75}\right)$ and a significant decrease in intensity at $340 \mathrm{~nm}$ (emission wavelength $\left(\lambda_{\max }\right)$ of tryptophan $\left.{ }^{47}\right)$. All kinetic parameters of the conjugated form of lysozyme changed, probably due to the structural modifications in the tertiary structure, particularly in the active site. Successful conjugation of lysozyme on SWCNT's improves its thermostability and pH stability thus making this nanobiocatalyst system an excellent candidate for biotechnology and biomedical applications. More interactions of urea with hydrophilic residues in conjugated lysozyme resulted in disrupting more intramolecular hydrogen bonds and protein denaturation. Our results showed more ionic dispersion potential for a chaotropic salt, $\mathrm{KSCN}$, in comparison with $\mathrm{KCl}$. At $70{ }^{\circ} \mathrm{C}$ and for a given rate constant, inactivation of both forms of lysozyme were under a first order kinetic. It should be noted that there is a great need for research in the area of SWCNT support for enzyme conjugation.

\section{Conflicts of interest}

There are no conflicts to declare.

\section{Acknowledgements}

Special thanks to Mrs Maryam Tavana for buffer preparation.

\section{References}

1 I. Willner, Science, 2002, 298, 2407-2408.

2 D. F. Emerich and C. G. Thanos, Expert Opin. Biol. Ther., 2003, 3, 655-663.

3 M. Sarikaya, C. Tamerler, A. K.-Y. Jen, K. Schulten and F. Baneyx, Nat. Mater., 2003, 2, 577-585.

4 A. Bianco, K. Kostarelos and M. Prato, Chem. Commun., 2011, 47, 10182-10188.

5 J. C. Cruz, P. H. Pfromm, J. M. Tomich and M. E. Rezac, Colloids Surf., B, 2010, 79, 97-104.

6 M. Puri, C. J. Barrow and M. L. Verma, Trends Biotechnol., 2013, 31, 215-216.

7 I. V. Pavlidis, T. Vorhaben, T. Tsoufis, P. Rudolf, U. T. Bornscheuer, D. Gournis and H. Stamatis, Bioresour. Technol., 2012, 115, 164-171.

8 I. Pavlidis, T. Tsoufis, A. Enotiadis, D. Gournis and H. Stamatis, Adv. Eng. Mater., 2010, 12, B179-B183.

9 S. Shah, K. Solanki and M. N. Gupta, Chem. Cent. J., 2007, 1, 1.

10 S. Boncel, A. Zniszczoł, K. Szymańska, J. Mrowiec-Białoń, A. Jarzębski and K. Z. Walczak, Enzyme Microb. Technol., 2013, 53, 263-270.

11 T. Raghavendra, A. Basak, L. M. Manocha, A. R. Shah and D. Madamwar, Bioresour. Technol., 2013, 140, 103-110.

12 A. van Blaaderen, Nature, 2006, 439, 545-546.

13 P. Asuri, S. S. Bale, R. C. Pangule, D. A. Shah, R. S. Kane and J. S. Dordick, Langmuir, 2007, 23, 12318-12321.

14 Q. Shi, D. Yang, Y. Su, J. Li, Z. Jiang, Y. Jiang and W. Yuan, J. Nanopart. Res., 2007, 9, 1205-1210.

15 S. H. Lee, T. T. N. Doan, K. Won, S. H. Ha and Y.-M. Koo, J. Mol. Catal. B: Enzym., 2010, 62, 169-172.

16 F. Bomboi, A. Bonincontro, C. La Mesa and F. Tardani, J. Colloid Interface Sci., 2011, 355, 342-347.

17 L. Zhang, S. Ramsaywack, H. Fenniri and T. J. Webster, Tissue Eng., Part A, 2008, 14, 1353-1364.

18 L. Sun, D. Li, U. D. Hemraz, H. Fenniri and T. J. Webster, J. Biomed. Mater. Res., Part A, 2014, 102, 3446-3451.

19 K. Lee, E. A. Silva and D. J. Mooney, J. R. Soc., Interface, 2011, 8, 153-170.

20 Z. Cheng and S.-H. Teoh, Biomaterials, 2004, 25, 1991-2001. 21 Z. Ma, C. Gao, J. Ji and J. Shen, Eur. Polym. J., 2002, 38, 22792284.

22 Y. Zhu, C. Gao, Y. Liu and J. Shen, J. Biomed. Mater. Res., Part A, 2004, 69, 436-443.

23 Y. Zhu, C. Gao and J. Shen, Biomaterials, 2002, 23, 48894895.

24 A. Matsuda, H. Kobayashi, S. Itoh, K. Kataoka and J. Tanaka, Biomaterials, 2005, 26, 2273-2279.

25 L. Y. Santiago, R. W. Nowak, J. P. Rubin and K. G. Marra, Biomaterials, 2006, 27, 2962-2969.

26 H. Koh, T. Yong, C. Chan and S. Ramakrishna, Biomaterials, 2008, 29, 3574-3582. 
27 X. Wang, D. Li, W. Wang, Q. Feng, F. Cui, Y. Xu and X. Song, Int. J. Biol. Macromol., 2003, 33, 95-100.

28 Z. Ding, J. Chen, S. Gao, J. Chang, J. Zhang and E. Kang, Biomaterials, 2004, 25, 1059-1067.

29 J.-D. Liao, S.-P. Lin and Y.-T. Wu, Biomacromolecules, 2005, 6, 392-399.

30 U. Hersel, C. Dahmen and H. Kessler, Biomaterials, 2003, 24, 4385-4415.

31 H. Sun, A. Wirsén and A.-C. Albertsson, Biomacromolecules, 2004, 5, 2275-2280.

32 W. Mattanavee, O. Suwantong, S. Puthong, T. Bunaprasert, V. P. Hoven and P. Supaphol, ACS Appl. Mater. Interfaces, 2009, 1, 1076-1085.

33 S. Smart, A. Cassady, G. Lu and D. Martin, Carbon, 2006, 44, 1034-1047.

34 A. Illanes, Enzyme biocatalysis: principles and applications, Springer Science \& Business Media, 2008.

35 L. Chronopoulou, G. Kamel, C. Sparago, F. Bordi, S. Lupi, M. Diociaiuti and C. Palocci, Soft Matter, 2011, 7, 2653-2662.

36 R. C. Barabino, D. N. Gray and M. H. Keyes, Clin. Chem., 1978, 24, 1393-1398.

37 D. T. Kim, H. W. Blanch and C. J. Radke, Langmuir, 2002, 18, 5841-5850.

38 T. Wei, M. A. Carignano and I. Szleifer, Langmuir, 2011, 27, 12074-12081.

39 K. Kubiak-Ossowska, M. Cwieka, A. Kaczynska, B. Jachimska and P. A. Mulheran, Phys. Chem. Chem. Phys., 2015, 17, 24070-24077.

40 E. S. Kirkor and A. Scheeline, J. Phys. Chem. B, 2001, 105, 6278-6280.

41 R. A. Silva, A. M. Carmona-Ribeiro and D. F. S. Petri, Int. J. Biol. Macromol., 2007, 41, 404-409.

42 J. V. Nicolini, N. S. de Resende and H. C. Ferraz, J. Chem. Technol. Biotechnol., 2015, 90, 739-746.

43 T. Imoto and K. Yagishita, Agric. Biol. Chem., 1971, 35, 11541156.

44 Z. Borzooeian, A. Safavi, M. Hossain Sheikhi, M. Aminlari and M. Mahdi Doroodmand, J. Exp. Nanosci., 2010, 5, 536547.

45 H.-M. Ding, L. Shao, R.-J. Liu, Q.-G. Xiao and J.-F. Chen, J. Colloid Interface Sci., 2005, 290, 102-106.

46 J. R. Lakowicz and B. R. Masters, J. Biomed. Opt., 2008, 13, 029901.

47 T. Imoto, L. S. Forster, J. Rupley and F. Tanaka, Proc. Natl. Acad. Sci. U. S. A., 1972, 69, 1151-1155.

48 R. Cundall, Time-resolved fluorescence spectroscopy in biochemistry and biology, Springer Science \& Business Media, 2013.

49 C. D. McGuinness, A. M. Macmillan, K. Sagoo, D. McLoskey and D. J. Birch, Appl. Phys. Lett., 2006, 89, 063901.
50 H. Huang, M. Zou, X. Xu, F. Liu, N. Li and X. Wang, TrAC, Trends Anal. Chem., 2011, 30, 1109-1119.

51 K.-C. Kao, T.-S. Lin and C.-Y. Mou, J. Phys. Chem. C, 2014, 118, 6734-6743.

52 A. J. Kirby, Nat. Struct. Mol. Biol., 2001, 8, 737.

53 C. Blake, L. N. Johnson, G. Mair, A. North, D. Phillips and V. Sarma, Proc. R. Soc. London, Ser. B, 1967, 167, 378-388.

54 S. Damodaran, J. Food Sci., 2005, 70, R54-R66.

55 V. Fainerman, E. Lucassen-Reynders and R. Miller, Colloids Surf., A, 1998, 143, 141-165.

56 C. H. Ramos and R. L. Baldwin, Protein Sci., 2002, 11, 17711778.

57 E. Taqieddin and M. Amiji, Biomaterials, 2004, 25, 19371945.

58 H. H. Weetall, Science, 1969, 166, 615-617.

59 R. Fernandez-Lafuente, J. Mol. Catal. B: Enzym., 2010, 62, 197-212.

60 X. Tadeo, M. Pons and O. Millet, Biochemistry, 2007, 46, 917923.

61 W. R. Cannon, N. D. Talley, B. A. Danzig, X. Liu, J. S. Martinez, A. P. Shreve and G. MacDonald, Biophys. Chem., 2012, 163, 56-63.

62 A. J. Richard, C.-C. Liu, A. L. Klinger, M. J. Todd, T. M. Mezzasalma and V. J. LiCata, Biochim. Biophys. Acta, Proteins Proteomics, 2006, 1764, 1546-1552.

63 L. A. Sikkink and M. Ramirez-Alvarado, Biophys. Chem., 2008, 135, 25-31.

64 R. Komsa-Penkova, R. Koynova, G. Kostov and B. G. Tenchov, Biochim. Biophys. Acta, Protein Struct. Mol. Enzymol., 1996, 1297, 171-181.

65 M. Boström, D. Williams and B. W. Ninham, Biophys. J., 2003, 85, 686-694.

66 M. Bončina, J. Reščič and V. Vlachy, Biophys. J., 2008, 95, 1285-1294.

67 J. W. Bye and R. J. Falconer, Protein Sci., 2013, 22, 1563-1570.

68 A. Hédoux, S. Krenzlin, L. Paccou, Y. Guinet, M.-P. Flament and J. Siepmann, Phys. Chem. Chem. Phys., 2010, 12, 13189-13196.

69 Y. Nozaki and C. Tanford, J. Biol. Chem., 1963, 238, 40744081.

70 D. B. Watlaufer, S. K. Malik, L. Stoller and R. L. Coffin, J. Am. Chem. Soc., 1964, 86, 508-514.

71 D. R. Robinson and W. P. Jencks, J. Am. Chem. Soc., 1965, 87, 2462-2470.

72 E. Finer, F. Franks and M. Tait, J. Am. Chem. Soc., 1972, 94, 4424-4429.

73 J. Tirado-Rives, M. Orozco and W. L. Jorgensen, Biochemistry, 1997, 36, 7313-7329.

74 B. J. Bennion and V. Daggett, Proc. Natl. Acad. Sci. U. S. A., 2003, 100, 5142-5147.

75 C. Albrecht, Anal. Bioanal. Chem., 2008, 390, 1223-1224. 